\title{
Current indications for the intrathoracic transposition of the omentum
}

\author{
Petre V. H. Botianu(D)
}

\begin{abstract}
Background: The intrathoracic transposition of the omentum (ITO) has been reported with more or less good results in various clinical circumstances but with no clear guidelines or indications.

Methodology and review: This article reviews the main clinical situations in which omento-plasty (OP) may be taken into consideration by the thoracic surgeons: mediastinitis and deep sternal infections after median sternotomy, reinforcement of the eso-gastric anastomosis after esophagectomy, prevention and treatment of the bronchial fistula after pulmonary resection, space-filling procedures for empyema, mediastinal tracheostomy, management of the infected intrathoracic vascular grafts / ventricular assist devices and heart OP. For each clinical situation we have performed a literature review with analysis of the most relevant published papers searching for an evidence-based approach for the use of the ITO/OP in thoracic surgery.
\end{abstract}

Conclusions: OP may be an elegant solution for a wide range of problems in thoracic surgery. In the published literature, there are mainly case-reports and relatively small series published resulting in a low level of evidence for both ITO as a surgical technique by itself, as well as for the use of OP in various clinical situations involving the chest structures. The indications for its use in thoracic surgery are based more on common sense and the lack of other solutions.

Keywords: Omentoplasty, Omentum, Mediastinitis, Median sternotomy, Eso-gastric anastomosis, Esophagectomy, Bronchial fistula, Space-filling procedures, Empyema, Mediastinal tracheostomy, Infected vascular grafts

\section{Background}

The omentum is well known as having an excellent plasticity and blood supply and its use has been reported in a great variety of defects with good results $[1,2]$. Although not very frequently used in thoracic surgery, omentoplasty (OP) may be an elegant solution for a wide range of problems, including the prevention and treatment of lifeendangering complications $[3,4]$. However, most of the published studies include relatively small series and for most of the clinical situations there are neither guidelines, nor prospective randomised studies to allow clear indications for its use in thoracic surgery. Since in most cases the available literature does not allow an evidenced-based approach due to the small number and the great heterogenicity of the patients, our aim was to provide an overview of the use of this specific surgical technique (OP) in the nowadays thoracic surgery practice. This paper presents

\section{Correspondence: botianu_petre@yahoo.com}

Surgery IV Discipline, M5 Department, University of Medicine and Pharmacy from Tirgu-Mures, 540091 Bujorului 2A, Tirgu-Mures, Romania and discusses the current indications for the intrathoracic transposition of the omentum (ITO), with specific considerations on the arguments and analysis of the available evidence for $\mathrm{OP}$ in certain clinical situations.

\section{Methodology}

We have performed a literature review concerning the use of ITO / OP in thoracic surgery using the PubMed and Medline databases up to may 2018 using the following combinations of MeSH terms: [Omentum, Omentoplasty, Epiploon] AND [Mediastinitis / Deep Sternal Infections / Median Sternotomy], [Esophagectomy / Eso-Gastric Anastomosis], [Bronchial Closure / Bronchial Fistula / Pulmonary Resection / Lobectomy / Pneumonectomy], [Empyema], [Mediastinal Tracheostomy], [Infected Vascular Graft], [Ventricular Assist Device / VAD], [Heart].

\section{Review}

We present a review concerning the indications and the main arguments for and against the use of the omentum

(c) The Author(s). 2019 Open Access This article is distributed under the terms of the Creative Commons Attribution 4.0 International License (http://creativecommons.org/licenses/by/4.0/), which permits unrestricted use, distribution, and 
flap (OF) in the following clinical situations: mediastinitis and deep sternal infections after median sternotomy, reinforcement of the eso-gastric anastomosis after esophagectomy, prevention and treatment of the bronchial fistula after pulmonary resection, space-filling procedures for empyema, mediastinal tracheostomy, management of the infected intrathoracic vascular grafts / ventricular assist devices and heart OP. An emphasys was put on the level of evidence for using OP in each of the aforementioned clinical situations.

Mediastinitis and deep sternal infections after median sternotomy are an excellent indication for OP, which may be used alone or together with other flaps (usually pectoralis), with or without skin grafts, in order to achieve complete and definitive wound healing [5-8]. In a meta-analysis of 16 observational studies including 1046 patients treated in units using both OF and muscle flaps for the treatment of mediastinitis / deep sternal infections, van Wingerdeen et al. (2011) found that there is no evidence to prove the superiority of reconstruction with muscle flaps versus a laparotomy-harvested OF, while the use of the omentum may be associated with a lower mortality and fewer complications [9]. The OF can be easily mobilized using a small upper midline laparotomy and brought to fill the anterior mediastinum after debridement and/or the use of negative pressure wound therapy. The possibility to mobilize the OF using a laparoscopic approach makes this flap even more attractive by avoiding the morbidity associated with laparotomy [10]. A specific but rare complication of OP for mediastinitis and deep sternal wound infections is the possibility to develop a retrosternal herniation of the abdominal viscera through the diaphragmatic defect; reoperation and treatment of this particular hernia is possible without compromising the OF [11].

Reinforcement of the eso-gastric anastomosis after esophagectomy is a relatively new but increasingly popular indication for the ITO. This technique involves the mobilization of a relatively small OF based on the gastro-epiploic arcade and the epiploic vessels together with the greater curvature of the stomach (Fig. 1 a), which is then used to wrap the anastomosis between the gastric tube and the upper esophageal stump (Fig. 1b). It may be used to reinforce both intrathoracic [12] and cervical [13] eso-gastric anastomosis. There are several published studies showing that this technique is associated with a significant reduction of the incidence $-2.9 \%$ vs $10.5 \%, \mathrm{POR}=0.28,95 \% \mathrm{CI}=0.17$ to 0.47 and $P<0.0001$ in the meta-analysis published by Wiggins in 2015, as well as the severity of the anastomotic fistulas [14], although it does not seem to reduce the overall mortality after esophagectomy [14-16]. Since this particular OF can be mobilized very easy and quick together with the gastric conduit without any additional morbidity, we may conclude that its use should be taken into consideration as a routine measure to reduce the morbidity after esophagectomy.

Quite interesting, we found no studies concerning the use of the OF to reinforce anastomoses after other types of esophageal reconstruction.

\section{Prevention and treatment of the bronchial fistula after pulmonary resection}

Reinforcement of the bronchial stump after lung resection is usually indicated in patients considered at highrisk for developing a bronchial fistula $[17,18]$ but the OF is rarely used in this situation since there are other more simple solutions not requiring an additional access to the abdominal cavity [19-21]. However, when a bronchial fistula develops after a pulmonary resection the use of an OF should be strongly taken into consideration if other less invasive solutions are not possible or have failed - usually after right pneumonectomy. The OF with its excellent vascularisation and plasticity allows a very easy and safe closure of the bronchial opening, even in the presence of active infection and fibrotic tissues (Fig. 2); there are several published papers with good results reported in small series of patients $[22,23]$ but we

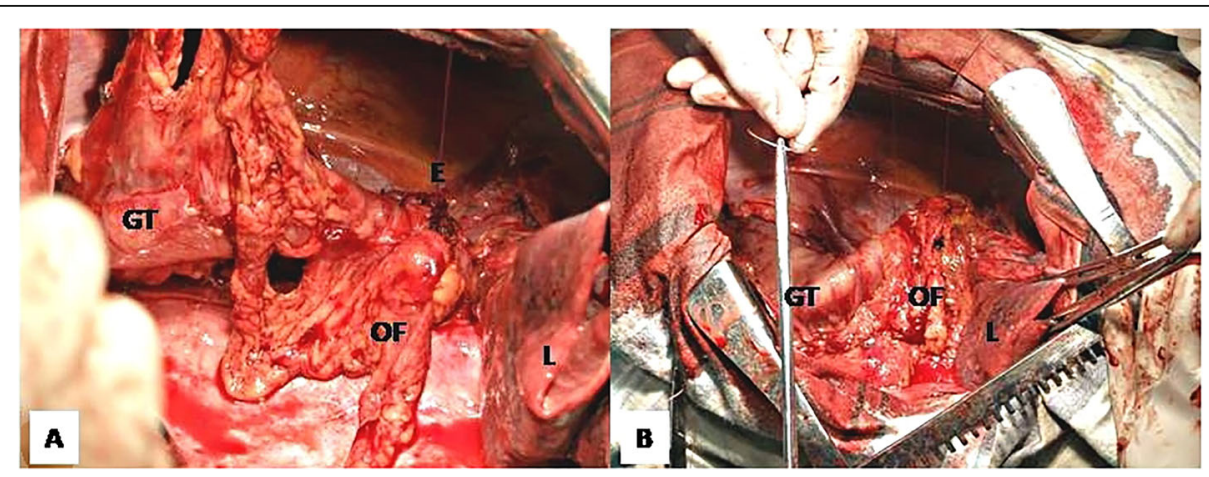

Fig. 1 Intrathoracic eso-gastric anastomosis reinforced by omental wrapping. Note that the OF is mobilized together with the greater curvature gastric tube (a) and then wrapped around the eso-gastric anastomosis (b) which will be completely covered by the OF. (GT - gastric tube, E - esophagus, L - lung) 
found no study comparing OP with other bronchial fistula closure techniques. Large airway defects not amenable to direct closure may be solved by the use of bioprosthetic materials covered by well-vascularised flaps - including the OF [24].

One of the classic main disadvantages of ITO/OP for both bronchial stump reinforcement and bronchial fistula closure is the need to perform a supplementary laparotomy, which requires to reposition the patient on the operating table, adds a significant increase of the operating time and is associated with a supplementary specific morbidity. D'Andrilli and colleagues recommend the transdiaphragmatic mobilization of the OF through the usual thoracotomy. Since closure of a bronchial fistula does not require a large volume flap, only a limited mobilization is usually required, thus involving a minimal dissection which may be performed safe and easy through a limited phrenotomy in the absence of peritoneal adhesions [25].

Space-filling procedures for empyema may benefit from the use of an OF, although its use in this condition involves a supplementary abdominal septic risk while most of the cases can be solved by thoracomyoplasty using neighbourhood muscle flaps [21, 26-29]. According to Le Fourn (1994) the presence of a bronchial fistula which may be closed using an omental patch, previous radiotherapy and a large posterolateral thoracotomy with sectioning of the latissimus dorsi are arguments to preferr OP [30]. Since the OF does not have a very large volume, it is necessary in most cases to add the use of other muscle flaps and/or a thoracoplasty in order to achieve a complete obliteration of the infected space [31, 32]. To note that the OF is frequently used for both the closure of the bronchial fistula and filling of the empyema cavity, alone or together with other muscle flaps while many of the studies dedicated to the space-filling procedures for empyema include cases solved by OP without clearly explaining the reason why the omentum was preferred over other flaps [33-37]. Intraparenchymatous infected cavities are nowadays extremely rare indications for space-filling procedures [38] while the omentum is difficult to mobilize inside a pulmonary cavity; in the available literature we found only case-reports with free $\mathrm{OF}$ transferred using microsurgery techniques for solving intrapulmonary infectious lesions [39].

\section{Mediastinal tracheostomy}

During this rarely performed procedure - usually indicated for advanced neck cancers, OP has been reported to prevent vascular erosion with fatal bleeding. Most series include a small number of patients with no comparison between OP versus pectoralis muscle flap [40, 41].

\section{Management of the infected intrathoracic vascular grafts}

This situation is known as a very difficult one with a poor outcome due to the association of sepsis and bleeding in patients with significant comorbidities. There is no standardized treatment with most cases requiring a multidisciplinary

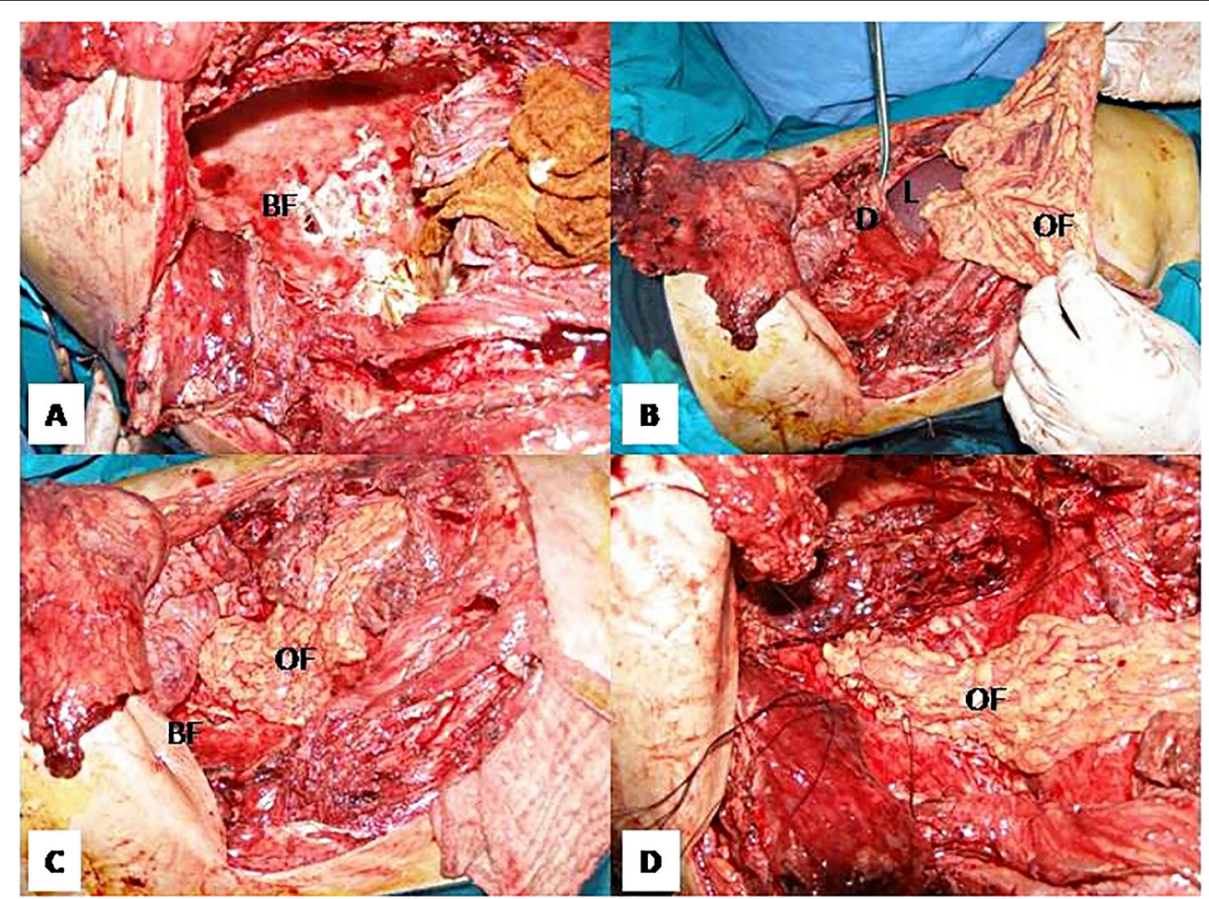

Fig. 2 Closure of a large bronchial fistula after right pneumonectomy during a space-filling procedure (a). The OF was mobilized through a phrenotomy (b) and fxed with separate stitches over the bronchial fistula $(\mathbf{c}, \mathbf{d})$ without performing a supplementary laparotomy (BF - bronchial fistula, D - diaphragm, $\mathrm{L}-$ liver) 
approach which includes more pharmacological, endovascular and open surgical options [42].

The OF is used for both wrapping the graft and filling the dead/infected mediastinal spaces, combined with other anti-infectious strategies. In selected cases, the in situ preservaton of the infected graft is possible by a combination of systemic and local antiinfectious therapy, local debridement and wrapping with well-vascularised flaps including OP [43]. In the available literature we found only case-reports and small series, the largest singlecenter study dedicated precisely to this subject being the one published by Shah et al. in 2013 who reported only one death in a series of 11 patients with infected aortic grafts treated by OP [44]. In a multi-center retrospective study on 58 patients with infected intrathoracic vascular prosthesis, Oda et al. (2015) found that the use of muscle or OF to wrap the infected grafts was associated with a reduction of the mortality but no comparative study OP versus muscle flaps was performed [45].

A particular situation is the development of an aortoesophageal fistula, which has a very high immediate fatal outcome potential while surgical repair is extremely challenging due to the complexity of the lesions and the presence of infection. The most succesfull strategy seems to be the one proposed recently by Nakamura and colleagues (2017) consisting in emergency graft replacement of the ruptured/perforated aorta and esophagectomy with mediastinal debridement to achieve local control of sepsis, as well as OP in order to protect the vascular graft which is implanted in a septic area [46]. Endovascular repair may allow an immediate temporary controle of the bleeding, which is usefull in the patients with haemorrhagic shock while an esophageal reconstruction in a later stage is possible if there are no other complications and the biological status of the patient allows another major procedure [46-48].

Prophylactic omental wrapping after the excision of infectious thoracic aorta aneurysms has been reported with good results in small series of patients [49-51]. In a series of 22 patients with infectious thoracic aortic aneurysms treated by excision and in situ grafting, Yamashiro et al. report better results in the patients with omental wrapping of the graft: with versus without omental wrapping operative mortality of 12.5 versus $50.0 \%$, $(p=0.06)$ while the 5 -year event-free survival rates were 84.6 versus $33.3 \%(p=0.025)$. However, these results should be interpretated with caution due to the small number of the patients involved [50].

Management of the infected ventricular assist devices used for end-stage heart diseases has been recently reported to benefit from OP in small series. The OF is used to wrap the pump and connection tubes, as well as to fill the infected mediastinum and/or the spaces surrounding the ventricular assist devices [52, 53]. Considering the increasing use of the ventricular assist devices in the treatment of end-stage heart diseases this may be an important indication for the use of the OF in the near future.

Heart omentopexy/OP in order to induce myocardial neovascularisation is an old idea. It was used as a surgical solution for ischemic heart disease before the development of modern cardiac surgery [54] but it was abandoned due to both poor results and the development of more efficient methods for treating coronary atherosclerosis [55]. Some recent experimental studies showed promising results by using hybrid strategies involving heart omentopexy/OP to enhance the myocardial revascularisation induced by various cell therapies $[56,57]$ but no translation to human clinical practice has been performed yet.

\section{Conclusions}

ITO/OP may be a solution for a wide range of problems in modern thoracic surgery. However, for most of the clinical situations analysed there is a low level of evidence to support its use and the indication to perform ITO/OP is based mainly on common sense and the lack of other alternatives, as well as a combination of easy mobilization and reduced associated morbidity. The possibility to perform the mobilization of the OF using a transdiaphragmatic [25] or laparoscopic [10, 58] approach may increase the indications for its use in the future. Thoracic surgeons should be familiar with the anatomy and the techniques of OF mobilization and ITO.

\section{Abbreviations \\ ITO: intrathoracic transposition of the omentum; OF: omentum flap; OP: omentoplasty}

\section{Acknowledgements}

Not applicable.

Author's contribution

Single author publication. The author read and approved the final manuscript.

\section{Funding}

This research was funded through an internal research grant by the University of Medicine and Pharmacy of Tirgu-Mures, Romania (CIGCS 2012).

\section{Availability of data and materials}

Data sharing not applicable to this article as no datasets were generated or analysed during the current study.

Ethics approval and consent to participate Not applicable.

Consent for publication

Not applicable.

Competing interests

The author declare that he/she has no competing interests. 
Received: 11 July 2018 Accepted: 28 May 2019

Published online: 10 June 2019

\section{References}

1. Micheau P. The greater omentum. Its role in reconstructive plastic surgery. Ann Chir Plast Esthet. 1995;40(2):192-207.

2. Botianu PV, Damian V, lonica S, et al. Extraperitoneal mobilization of the omentum--analysis of a personal series of 12 patients. Chirurgia (Bucur). 2012;107(5):611-5.

3. Levashev YN, Akopov AL, Mosin IV. The possibilities of greater omentum usage in thoracic surgery. Eur J Cardiothorac Surg. 1999;15(4):465-8.

4. Shrager JB, Wain JC, Wright CD, et al. Omentum is highly effective in the management of complex cardiothoracic surgical problems. J Thorac Cardiovasc Surg. 2003;125(3):526-32.

5. Chittithavorn V, Rergkliang C, Chetpaophan A, Simapattanapong T. Singlestage omental flap transposition: modality of an effective treatment for deep sternal wound infection. Interact Cardiovasc Thorac Surg. 2011;12(6):982-6.

6. De Brabandere $\mathrm{K}$, Jacobs-Tulleneers-Thevissen D, Czapla J, et al. Negativepressure wound therapy and laparoscopic omentoplasty for deep sternal wound infections after median sternotomy. Tex Heart Inst J. 2012;39(3):367-71.

7. Spindler N, Etz CD, Misfeld M, et al. Omentum flap as a salvage procedure in deep sternal wound infection. Ther Clin Risk Manag. 2017;23(13):1077-83.

8. Kaul P. Sternal reconstruction after post-sternotomy mediastinitis. J Cardiothorac Surg. 2017;12(1):94.

9. van Wingerden JJ, Lapid O, Boonstra PW, de Mol BA. Muscle flaps or omental flap in the management of deep sternal wound infection. Interact Cardiovasc Thorac Surg. 2011;13(2):179-87.

10. van Wingerden JJ, Coret ME, van Nieuwenhoven CA, Totté ER. The laparoscopically harvested omental flap for deep sternal wound infection. Eur J Cardiothorac Surg. 2010;37(1):87-92.

11. Hashimoto M, Yamauchi A, Shimabuku M, Higami T. Herniation of transverse colon into mediastinum after pedicled omental grafting for mediastinitis: report of a case. Gen Thorac Cardiovasc Surg. 2015;63(11):620-2.

12. Sepesi B, Swisher SG, Walsh GL, et al. Omental reinforcement of the thoracic esophagogastric anastomosis: an analysis of leak and reintervention rates in patients undergoing planned and salvage esophagectomy. J Thorac Cardiovasc Surg. 2012;144(5):1146-50

13. Zhou D, Liu QX, Deng XF, et al. Anastomotic reinforcement with omentoplasty reduces anastomotic leakage for minimally invasive esophagectomy with cervical anastomosis. Cancer Manag Res. 2018;10:257-63.

14. Wiggins T, Markar SR, Arya S, Hanna GB. Anastomotic reinforcement with omentoplasty following gastrointestinal anastomosis: a systematic review and meta-analysis. Surg Oncol. 2015;24(3):181-6.

15. Yuan Y, Zeng X, Hu Y, Xie T, Zhao Y. Omentoplasty for oesophagogastrostomy after oesophagectomy. Cochrane Database Syst Rev. 2014 Oct;10(2):CD008446.

16. Chen L, Liu F, Wang K, Zou W. Omentoplasty in the prevention of anastomotic leakage after oesophagectomy: a meta-analysis. Eur J Surg Oncol. 2014;40(12):1635-40.

17. Di Maio M, Perrone F, Deschamps C, Rocco G. A meta-analysis of the impact of bronchial stump coverage on the risk of bronchopleural fistula after pneumonectomy. Eur J Cardiothorac Surg. 2015;48(2):196-200.

18. Llewellyn-Bennett $R$, Wotton $R$, West $D$. Prophylactic flap coverage and the incidence of bronchopleural fistulae after pneumonectomy. Interact Cardiovasc Thorac Surg. 2013;16(5):681-5.

19. Sfyridis PG, Kapetanakis El, Baltayiannis NE, et al. Bronchial stump buttressing with an intercostal muscle flap in diabetic patients. Ann Thorac Surg. 2007:84(3):967-71.

20. Taghavi S, Marta GM, Lang G, et al. Bronchial stump coverage with a pedicled pericardial flap: an effective method for prevention of postpneumonectomy bronchopleural fistula. Ann Thorac Surg. 2005:79(1):284-8.

21. Botianu P, Botianu A. Use of the serratus anterior muscle flap for postoperative empyema -- a single center experience with 25 consecutive cases. Chirurgia (Bucur). 2013;108(5):695-9.

22. Chichevatov D, Gorshenev A. Omentoplasty in treatment of early bronchopleural fistulas after pneumonectomy. Asian Cardiovasc Thorac Ann 2005:13(3):211-6.

23. Jiang F, Huang J, You Q, et al. Surgical treatment for bronchopleural fistula with omentum covering after pulmonary resection for non-small cell lung cancer. Thorac Cancer. 2013;4(3):249-53.
24. Udelsman BV, Eaton J, Muniappan A, et al. Repair of large airway defects with bioprosthetic materials. J Thorac Cardiovasc Surg. 2016;152(5):1388-97.

25. D'Andrilli A, Ibrahim M, Andreetti C, et al. Transdiaphragmatic harvesting of the omentum through thoracotomy for bronchial stump reinforcement. Ann Thorac Surg. 2009;88(1):212-5.

26. Botianu PV, Botianu AM, Dobrica AC, Bacarea V. Intrathoracic transposition of the serratus anterior muscle flap--personal experience with 65 consecutive patients. Eur J Cardiothorac Surg. 2010;38(6):669-73.

27. Botianu PV, Botianu AM, Bacarea V, Dobrica AC. Thoracodorsal versus reversed mobilisation of the latissimus dorsi muscle for intrathoracic transposition. Eur J Cardiothorac Surg. 2010;38(4):461-5.

28. Lakranbi M, Rabiou S, Belliraj L, et al. What place for the thoracostomythoracomyoplasty in the management of the chronic pleural empyema? Rev Pneumol Clin. 2016;72(6):333-9.

29. Fournier I, Krueger T, Wang Y, Meyer A, Ris HB, Gonzalez M. Tailored thoracomyoplasty as a valid treatment option for chronic postlobectomy empyema. Ann Thorac Surg. 2012:94(2):387-9.

30. Le Fourn B, Lebatard-Sartre JY, Gousset-Lejeune F, et al. Use of the omentum in the treatment of chronic thoracic empyema. Ann Chir Plast Esthet. 1994;39(6):715-24.

31. Botianu PV, Botianu AM, Bacarea VC. Muscle flaps and thoracomyoplasty as a re-redo procedure for postoperative empyema. Thorac Cardiovasc Surg. 2016;64(3):252-7.

32. Botianu PV, Botianu AM. Thoracomyoplasty in the treatment of empyema: current indications, basic principles, and results. Pulm Med. 2012;2012:418514

33. Kitano M. Omentoplasty in thoracic surgery. Gen Thorac Cardiovasc Surg. 2008:56(10):483-9.

34. Politi L, Scanagatta P, Salani A, et al. Intrathoracic omentoplasty in the treatment of pleural cavity secondary to stabilized bronchial fistula. Minerva Chir. 2004:59(5):495-9.

35. Duan M, Chen G, Wang T, et al. One-stage pedicled omentum majus transplantation into thoracic cavity for treatment of chronic persistent empyema with or without bronchopleural fistula. Eur J Cardiothorac Surg. 1999:16(6):636-8.

36. Botianu AM, Botianu PV. Modified thoraco-mediastinal plication (Andrews thoracoplasty) for post-pneumonectomy empyema: experience with 30 consecutive cases. Interact Cardiovasc Thorac Surg. 2013;16(2):173-7.

37. Petrov D, Dzhambazov V , TS M, et al. Omentoplasty in surgical management of postpulmonectomy pleural empyema. Khirurgiia (Sofiia). 1999:55(6):13-5.

38. Botianu PV, Botianu AM. Muscle flaps and thoracomyoplasty: alternative solution for unresectable primary pulmonary abscesses. Thorac Cardiovasc Surg. 2013;61(7):626-30

39. Shimizu J, Arano Y, Adachi I, et al. Intractable lung abscess successfully treated with cavernostomy and free omental plombage using microvascular surgery. Gen Thorac Cardiovasc Surg. 2009;57(11):616-21.

40. Kuwabara Y, Sato A, Mitani M, et al. Use of omentum for mediastinal tracheostomy after total laryngoesophagectomy. Ann Thorac Surg. 2001; 71(2):409-13.

41. Martins AS, Lage HT, Lopes LR, Brandalise NA. Use of omentum pedicled graft to protect great vessels in gastric transposition for pharyngoesophageal cancer. J Surg Oncol. 1999;70(3):181-4.

42. Kahlberg A, Melissano G, Mascia D, et al. How to best treat infectious complications of open and endovascular thoracic aortic repairs. Semin Vasc Surg. 2017:30(2-3):95-102.

43. Tossios P, Karatzopoulos A, Tsagakis K, et al. Treatment of infected thoracic aortic prosthetic grafts with the in situ preservation strategy: a review of its history, surgical technique, and results. Heart Lung Circ. 2014;23(1):24-31.

44. Shah S, Sinno S, Vandevender D, Schwartz J. Management of thoracic aortic graft infections with the omental flap. Ann Plast Surg. 2013;70(6):680-3.

45. Oda T, Minatoya K, Kobayashi J, et al. Prosthetic vascular graft infection through a median sternotomy: a multicentre review. Interact Cardiovasc Thorac Surg. 2015;20(6):701-6.

46. Nakamura T, Yamamoto M, Yamazato T, et al. Surgical strategy of esophageal resection and reconstruction for aortoesophageal fistula. Dis Esophagus. 2017:30(9):1-7.

47. Kawamoto S, Sato M, Motoyoshi N, et al. Outcomes of a staged surgical treatment strategy for aortoesophageal fistula. Gen Thorac Cardiovasc Surg. 2015;63(3):147-52.

48. Yamazato T, Nakamura T, Abe N. Surgical strategy for the treatment of aortoesophageal fistula. J Thorac Cardiovasc Surg. 2018;155(1):32-40. 
49. Kuniyoshi Y, Koja K, Miyagi K, et al. Graft for mycotic thoracic aortic aneurysm: omental wrapping to prevent infection. Asian Cardiovasc Thorac Ann. 2005;13(1):11-6.

50. Yamashiro $S$, Arakaki $R$, Kise $Y$, et al. Potential role of omental wrapping to prevent infection after treatment for infectious thoracic aortic aneurysms. Eur J Cardiothorac Surg. 2013;43(6):1177-82.

51. Lau C, Gaudino M, de Biasi AR, et al. Outcomes of open repair of mycotic descending thoracic and thoracoabdominal aortic aneurysms. Ann Thorac Surg. 2015;100(5):1712-7.

52. Sajjadian A, Valerio IL, Acurturk O, et al. Omental transposition flap for salvage of ventricular assist devices. Plast Reconstr Surg. 2006;118(4):919-26.

53. Pieri M, Müller M, Scandroglio AM, et al. Surgical treatment of mediastinitis with omentoplasty in ventricular assist device patients: report of referral center experience. ASAIO J. 2016;62(6):666-70.

54. O'Shaughnessy L. Surgical treatment of cardiac ischemia. Lancet. 1937(1):185-94.

55. Costa F, Ariotti S, Valgimigli M, Kolh P, Windecker S, Task force on myocardial revascularization of the European Society of Cardiology (ESC) and the European Association for Cardio-Thoracic Surgery (EACTS). Perspectives on the 2014 ESC/EACTS guidelines on myocardial revascularization: fifty years of revascularization: where are we and where are we heading? J Cardiovasc Transl Res. 2015;8(4):211-20.

56. Kanamori T, Watanabe G, Yasuda T, et al. Hybrid surgical angiogenesis: omentopexy can enhance myocardial angiogenesis induced by cell therapy. Ann Thorac Surg. 2006;81(1):160-7.

57. Lilyanna S, Martinez EC, Vu TD, et al. Cord lining-mesenchymal stem cells graft supplemented with an omental flap induces myocardial revascularization and ameliorates cardiac dysfunction in a rat model of chronic ischemic heart failure. Tissue Eng Part A. 2013;19(11-12):1303-15.

58. Botianu P, Botianu AM, Chirtes R, Bacarea A. Laparoscopic mobilization of an omental flap for a chronic Scarpa triangle suppuration after vascular graft infection. Chirurgia (Bucur). 2015;110(6):573-6.

\section{Publisher's Note}

Springer Nature remains neutral with regard to jurisdictional claims in published maps and institutional affiliations.

Ready to submit your research? Choose BMC and benefit from:

- fast, convenient online submission

- thorough peer review by experienced researchers in your field

- rapid publication on acceptance

- support for research data, including large and complex data types

- gold Open Access which fosters wider collaboration and increased citations

- maximum visibility for your research: over $100 \mathrm{M}$ website views per year

At $\mathrm{BMC}$, research is always in progress.

Learn more biomedcentral.com/submissions 